Ind. Health, 1973, 11, 95.

\title{
STUDY ON HEINZ BODIES
}

\author{
Sumiko ISHIZU, Masayasu MINAMI and Kōtarō YAMAMURA \\ Department of Pubulic Health, Tokyo Women's Medical College, \\ Kawadacho, Shinjuku-ku, Tokyo
}

(Received July 3, 1973)

\begin{abstract}
Heinz body was studied morphologically using the histochemical and electromicroscopic methods. The result shows that one of the chemical components of Heinz body is denaturated hemoglobin and the methemoglobin formation will precipitate Heinz body development.
\end{abstract}

In 1890 , Heinz, $\mathrm{R}^{1)}$ found some corpuscles like buttons having high degree light refractive nature in the erythrocytes of rabbits intoxicated with phenylhydrazine, and observed precisely that they are localized in the circumference of the cells, and on collapse of cells by pressure they suspend in blood-plasma, and they are tingeable with basic coloring matters such as methyl violet.

At that time, Heinz named this corpuscles as "Blau Körper" from the view in the vital staining by methyl violet, but at present they are called Heinz body in general. Following these observations by Heinz in the early stage, it became noticed by many workers that this body is liable to appear at the time of intoxication by so-called aromatic nitro-amide compounds such as aniline, nitrobenzene, toluidine, hydroxylamine and so on, and a characteristic point lies in the formation of methemoglobin by the oxidative action of these chemicals upon the blood.

Namely, Heinz body (hereafter abbreviated as $\mathrm{H}$ bcdy) presented several problems interesting not only in its morphological peculiarity but also in hemoglobin chemistry, and it became the favorable objects of investigations for morphologists or biochemists, leading to the accumulation of numerous experimental results.

On the other hand, in pararell to these basal investigations, the significance of the occurrence of $\mathrm{H}$ bodies attracted the attention in clinical fields, Ehrlich $\mathrm{P}_{.}{ }^{2}$ attached importance from early days to the relation of $\mathrm{H}$ bodies to methemoglobin as well as the revelation of anemina, and Grosse, E., Bock, M., Hellrung, F. ${ }^{3)}$ et al. emphasized the value in the early diagnosis.

Especially in the first world war, the intoxication due to aromatic nitroamide occurred frequently (T.N.T. intoxication in this case) and in place of methemoglobin measurement which is difficult in the mannual procedure, the examination of $\mathrm{H}$ bodies were practiced actively in the hygienical control, which attracted the interest of clinical as well as factory physicians.

The attraction of further interest in $\mathrm{H}$ bodies by general physicians, however, 


\section{S. ISHIZU, M. MINAMI AND K. YAMAMURA}

is thought to depend upon the fact that Moeschlin, S.4) et al. found in 1940 that hemolytic anemia brought about at the intoxication due to sulfonamide and its derivatives is caused by the formation of $\mathrm{H}$ bodies of erythrocytes and concerning these facts, one series of research work was communicated.

Intoxication due to these therapeutic medicines is now yet occurring ${ }^{5,6)}$ occasionally and in this case, the examination of $\mathrm{H}$ bodies is one element of the examination, having an important significance for the differential diagnosis.

Since several years ago, the authors ${ }^{7)}$ made clinical observations from the standpoint of the factory hygienical control for workers at dye manufacturing factories and chemical plants to study the significance in the early diagnosis of $\mathrm{H}$ bodies in addition to the experimental investigation in the real nature, and here the results obtained so far by the authors are presented anticipating the comment.

\section{Morphological View and Staining Character of H Body}

As stated above, the morphological peculiarity of $\mathrm{H}$ body lies in that they are localized in the circumference of erythrocytes as spherical enclosures, and in many cases ene or two of them are found per one erythrocyte, and in addition to the view above, it was also noticed that they become larger gradually in the living body until a size of $1-2 \mu$ and at last disappear from the blood flow.

In the authors' result ${ }^{7)}$ observed on rabbits intoxicated by p-C.N.B. (paranitrochlorobenzene) also, they merely appeared as fine granules within a short period (about 4-6 hr, in this case) after the administration of a poison, but with the elapse of time, they increased their sizes gradually until they turned to small corpuscles of $1-2 \mu$ size being clearly noticed in almost whole erythrocytes after 18$24 \mathrm{hr}$. (Fig. 1)

Besides, the interesting poit in this case is that the spots-like granules in the

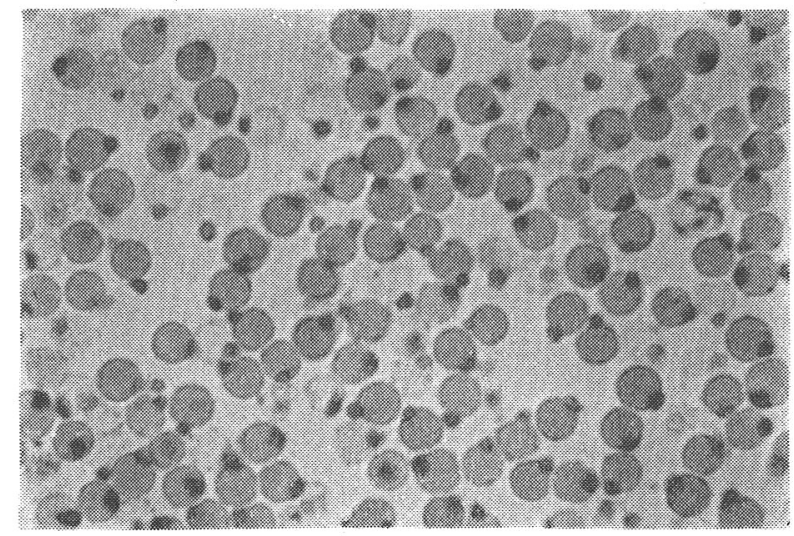

Fig. 1. Heinz bodies in erythrocytes of rabbits intoxicated with p-C.N.B. (paranitrochlorobenzene)-(fixed with formaline, stained with acid fuchsin after $24 \mathrm{hr}$ ) 


\section{STUDY ON HEINZ BODIES}

early stage appear as black granules showing active Brownian motion under the inspection of the same process by a phase microscope, and of late Yoshidas), Koyama $^{9)}$ et al. have observed similar appearances and are going to inquire into the formation of $\mathrm{H}$ body from the standpoint of these facts.

On the other hand, there are many investigations attempting to elucidate the real nature of this corpuscle basing upon the electronmicroscopical figures, and recently Pernis, B. ${ }^{10)}$ made an observation of the erythrocytes of guinea pigs intoxicated by phenylhydrazine and described that $\mathrm{H}$ body is homogeneous, has no definite structure, and appears not in specially intimate contact with the membrane of erythrocyte.

The authors inspected the ultra-thin section of erythrocytes containing $\mathrm{H}$ bodies fixed with osmic acid with an electronic microscope in the exaggeration of fifty thousand times and found that $\mathrm{H}$ body has no specially fixed structure and has almost the same density as hemoglobin in the surroundings.

As for the peculiarity in the staining of $\mathrm{H}$ bodies, it has been stated ${ }^{11)}$ that they are well stained by basic coloring matters such as brilliant cresyl blue, nile blue, and methyl violet, and also by a part of acidic coloring matters such as acid fuchsin and eosine as described in the early reports of Heinz.

The authors have confirmed until now that $\mathrm{H}$ bodies can be searched by

Table 1. View on the histological chemistry of heinz bodies.

\begin{tabular}{llc}
\hline \multicolumn{1}{c}{ Staining method } & Result \\
\hline & Daddi's method & - \\
& Kawamura, Yazaki's method & + \\
& Oil red-O & - \\
Lipoid & Sudan black-B & - \\
& Smith dietrich's method & + \\
& Osmic acid & - \\
& Nile blue & + \\
\hline \multirow{2}{*}{ Protein } & Hg-BPB & - \\
& Millon reaction & - \\
& Xantho protein reaction & - \\
\hline SH & Yasuma, Ichikawa method & + \\
\hline Nucleic acid & Bentt's methed, Mescon et Flesch's modified method & - \\
\hline Hemoglobin & Methyl green pyronine & + \\
\hline Iron & Patent blue & + \\
\hline \multirow{2}{*}{ Lugar } & Lepehne's method & + \\
\hline
\end{tabular}




\section{S. ISHIZU, M. MINAMI AND K. YAMAMURA}

supravital staining of fixed staining using sixteen kinds of basic coloring matters along with six kinds of acidic coloring matters.

But the analogical inference of the chemical composition of $\mathrm{H}$ bodies is naturally impossible only from the view on these stainings, and in order to supplement the information on this point even a little, the authors made a precise inspection by way of histological chemistry as described in the following and investigated the peculiarity. Table 1 and Fig. 2 are the synopsis of the result, presenting an evidence for lipoid, protein, hemoglobin, $\mathrm{SH}$ radical and so on, whereas in respect to nucleic acid, sugar, and iron reaction, negative results were obtained.?

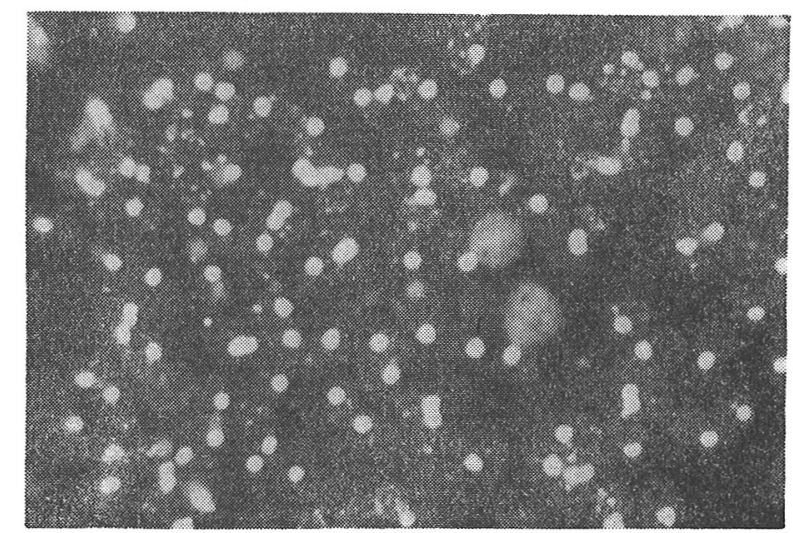

Fig. 2. Histological chemistry of Heinz bodies, fluorescence positive (phenol auramine method).

This view agrees well with the result by Hartwich, W. ${ }^{12)}$, Suzuki, T. ${ }^{13)}$, Hugo, $\mathrm{K}^{14)}$ et al. that $\mathrm{H}$ body contains mainly lipoid, protein, and hemoglobin as found in chemical analysis, and in addition, it was elucidated that $\mathrm{H}$ bodies contain $\mathrm{SH}$ group.

\section{H Bodies And Methemoglobin}

The relation between $\mathrm{H}$ bodies and methemoglobin has been fully studied for a long time, because chemicals liable to give rise to $\mathrm{H}$ bodies have an oxidative action upon the blood on one hand, and they often form methemoglobin, but still there remain many obscure points at present and yet no consensus of opinion has been found.

Regarding the results on the mutual relation in the past, Gutstein, M., Wallbach, G. ${ }^{15)}$ et al. stated according to their experimental results that $\mathrm{H}$ bodies appeard abundantly despite that methemoglobin was not detectable, and Webster, S.H. ${ }^{16)}$ obtained similar results in which no special connection was found between $\mathrm{H}$ bodies and methemoglobin. .

Moreover Heubner, W. ${ }^{17,18)}$ Kiess, M. and Seipelt, L. ${ }^{19)}$ et al. also described 


\section{STUDY ON HEINZ BODIES}

that the formation of methemoglobin, the appearance of $\mathrm{H}$ bodies, the formation of verdoglobin and so on will be a respecitively independent phenomena.

Koile $^{20)}$ also wrote a similar view. But conversely Moeschlin, S. ${ }^{21}$, Hughes, J.P. ${ }^{22)}$ et al. laid emphasis on the mutually intimate relation in the clinical and experimental researches. The authors, in order to investigate in this point, pursued punctually the relation between both as regards rabbits intoxicated by p-C.N.B. mentioned above.

Fig. 3 gives the quantitative change of both after the intoxication, indicating a specific course that after the administration of the poison (in this case, $0.5 \mathrm{~g} / \mathrm{kg}$ subcutaneous injection of p-C.N.B. dissolved in olive oil), methemoglobin increases within several hours, once decreases after $12 \mathrm{hr}$ or so, and again increase after 18-24 $\mathrm{hr}$, and soon after then, it became not detectable in the blood.
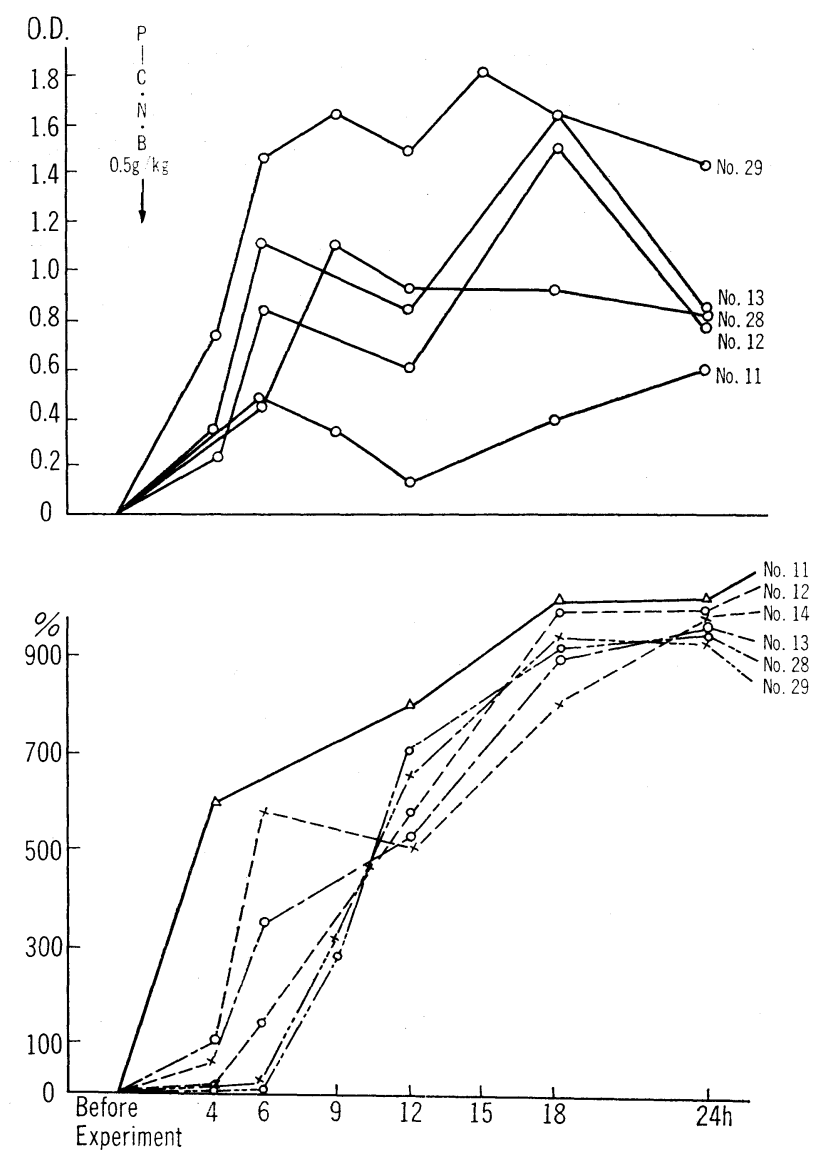

Fig. 3. Change in the formation of Met-Hb in rabbits intoxicated by p-C.N.B. and the formation of Heinz bodies with the elapse of time.

Note: No. in the figure indicates the animal number. 


\section{S. ISHIZU, M. MINAMI AND K. YAMAMURA}

$\mathrm{H}$ bodies seemed to be perfected (or enlarged) almost in parallel with the second increasing courve of methemoglobin.

From this result, the authors supposed that the increase of methemoglobin in the early stage has a connection with the sign of the formation of $\mathrm{H}$ bodies, and methemoglobin increasing secondly after once decreased might be relative to the perfection of $\mathrm{H}$ bodies.

And, in this case, both methemoglobin which increased in the early stage and one which increased secondly are estimated as identical methemoglobin so far as estimated by Evelyn-Malloy's method, but they do not necessarily seem to have same quality and function, and although two or three interesting views have been obtained $^{23)}$ on this point, the authors wish to abridge in this time. But they morely desire to describe, seeing from the experimental result, that some intimate connection is also infered to exist between methemoglobin and the formation of $\mathrm{H}$ bodies.

In regard to this point, numerous experimental results in the past did not necessarily give the point of agreement, and as for this fact, we must take the precisity in the estimation of methemoglobin into consideration and besides, as it was experienced that the amount of methemoglobin changes variously according to the kind of animals, the kind of poisons, the time elapsed after intoxication and so on, the necessity to mind such points more deeply than ever is keenly felt.

\section{Chemical Composition of H Bodies}

It seems appropriate to state that the chemical composition of $\mathrm{H}$ bodies is almost obscure.

There has hardly been clarified except that it is insoluble in solvents such as alchol or ether and water, soluble in caustic soda, glacial acetic acid, and the like and contains mainly lipoid, protein and hemoglobin and so on.

Among constituents contained, only some informations have been made upon the study on hemoglobin, and on this, the authors also have made some investigations, which will be described here.

In the early time, Hartwich ${ }^{24)}$ evidensed that $\mathrm{H}$ bodies contain hemoglobin derivatives in some form whatever it may be, whether it is hemin or hematoporphyrin, and Heubner, W. ${ }^{25)}$ said that this may be Verdoglobin, and Koike ${ }^{26)}$ also supported this concept basing upon the absorption figure at Soret band.

Moreover Kajiro, Aoki ${ }^{27)}$ et al. evidenced from the absorption figures of $\mathrm{H}$ bodies after the treatment with $\mathrm{NaOH}$ and $\mathrm{Na}_{2} \mathrm{~S}_{2} \mathrm{O}_{4}$ that a certain decomposition product (presumably choleglobin) which has an absorption in the red region is mingled in it in addition to hemoglobin not yet decomposed.

The authors, receiving the guidance by Dr. Kajiro et al. abovementioned (Biochemical Department, Nihon Medical College), made an experiment in which erythrocytes containing $\mathrm{H}$ bodies were submitted to hemolysis, centrifuged, and excluded 


\section{STUDY ON HEINZ BODIES}

the stroma, and a large number of $\mathrm{H}$ bodies repeatedly rinsed with distilled water were treated with $\mathrm{NaOH}$ and $\mathrm{H}_{2} \mathrm{~S}_{2} \mathrm{O}_{4}$, and its absorption figure was observed under visible ray.

Fig. 4 shows its absorption figure which seems probably to be choleglobin having an absorption at $610-620 \mathrm{~nm}$ in addition to the absorption of hemochrome degenerated by alkali.

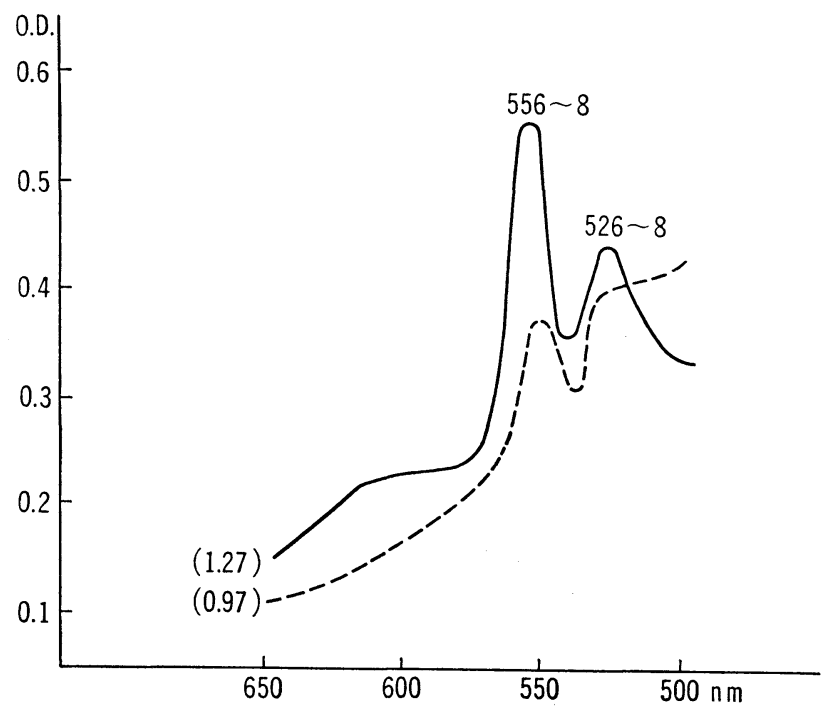

Fig. 4. Change of absorption figure of Heinz bodies with time (intoxicated with p-C.N.B., after $24 \mathrm{hr}$ and $96 \mathrm{hr}$ ) treated with $\mathrm{N} / 10 \mathrm{NaOH}, \mathrm{Na}_{2} \mathrm{~S}_{2} \mathrm{O}_{4}$.

Besides, this absorption figure appeared only in a fairly early stage about 24 $\mathrm{hr}$ after intoxication, and it was characteristic that this completely disappeared after that. $(48-72 \mathrm{hr})$

Namely it was found that choleglobin may be detected temporarily about 24 $\mathrm{hr}$ after intoxication. This fact is regarded to be concurrent with the fact that $\mathrm{H}$ bodies after about $24 \mathrm{hr}$ take green color to the naked eye and turn gradually to brown or yellowish brown color with the elapse of time. At all events, it seems to have been proved that $\mathrm{H}$ bodies contain hemoglobin related substances, and in addition, oxidation proceeds on the way to the perfection of $\mathrm{H}$ bodies.

But at present, the mechanism in the development of such phenomena lies within the extent of cojecture. Nevertheless, it cannot be denied that globin denaturation by poison itself or its metabolites precedes causing the oxidative cleavage of hem part.

In addition to above-mentioned hemoglobin related substances, there are some results studied on lipoid, protein, and so on, which are contained in $\mathrm{H}$ bodies, but sufficient informations have not yet been obtained in the recent state. 


\section{S. ISHIZU, M. MINAMI AND K. YAMAMURA}

\section{Clinical Observation of H Bodies}

As the report of clinical observation on $\mathrm{H}$ bodies, cases suffering from so-called industrial intoxication by such as aniline, nitrobenzen, as well as cases intoxicated by therapeutic medicines such as sulfonamide, antifebrin, and so on, exist toghther, and references on them amount to a fairly large numbers as mentioned in the preceding literature ${ }^{28)}$.

From the standpoint of factory hygienic control, the authors examined $\mathrm{H}$ bodies in respect to persons handling aromatic nitro compounds at dye factories, the result of which will be presented here.

The object of this investigation was a certain dye chemical factory where nitrochlorobenzene was prepared by the nitration of chlorobenzene in the way that chlorobenzene and mixed acid were mingled in a nitration kettle, and there were possibilities to suffer from intoxication by the effect of chemicals at places for the nitration process.

This inclination is especially large in summer, and workers became of pale faces, often complaining dizziness, headache, nausea and other symptoms.

Table 2. View on blood of workers dealing with p-C.N.B.

\begin{tabular}{|c|c|c|c|c|c|c|c|c|c|c|c|c|}
\hline Name & $\mathrm{K} \cdot \mathrm{X}$ & $\mathrm{T} \cdot \mathrm{X}$ & M. X & $0 . x$ & H. X & S. X & $\mathrm{I} \cdot \mathrm{X}$ & $0 . \mathrm{X} \mid$ & $\mathrm{I} \cdot \mathrm{X}$ & E. X & $\mathrm{K} \cdot \mathrm{X}$ & H. X \\
\hline Age & 39 & 35 & 21 & 32 & 44 & 44 & 32 & 40 & 33 & 35 & 34 & 29 \\
\hline Term in Service & 3 y. & $3 \mathrm{y}$. & $17 \mathrm{y}$. & $\begin{array}{c}1 \mathrm{y} . \\
\& 7 \mathrm{~m}\end{array}$ & $4 \mathrm{~m}$. & $13 \mathrm{y}$. & $7 \mathrm{y}$. & $7 \mathrm{y}$. & $5 \mathrm{~m}$. & $1 \mathrm{y}$. & $7 \mathrm{y}$. & $\begin{array}{l}6 \mathrm{y} . \\
\& 7 \mathrm{~m}\end{array}$ \\
\hline Dealing Substance & $\mathrm{p}_{-}^{-}$ & " & $"$ & $" \prime$ & " & $"$ & $" \prime$ & " & $" \prime$ & $" \prime$ & $" \prime$ & $" \prime$ \\
\hline $\begin{array}{l}\text { Number of Ery- } \\
\text { throcyte (million) }\end{array}$ & 3.30 & 3.60 & 3.66 & 3.92 & 3.55 & 3. 71 & 3.29 & 3.66 & 3.40 & 4.56 & 3.76 & 3.74 \\
\hline Hemoglobin $\mathrm{g} / \mathrm{dl}$ & 11.4 & 11.4 & 11.6 & 11.5 & 11.0 & 13.4 & 11.8 & 11.1 & 11.5 & 11.5 & 12.5 & 13.4 \\
\hline $\begin{array}{l}\text { Volume of Ery- } \\
\text { throcyte }(\%)\end{array}$ & 38.1 & 38.9 & 37.5 & 40.0 & 40.7 & 41.2 & 33.9 & 36.8 & 38.0 & 42.6 & 39.7 & 42.2 \\
\hline $\begin{array}{l}\text { Heinz bodies } \\
(0 / 00)\end{array}$ & 22 & 72 & 281 & 13 & 5 & 16 & 0 & 0 & 0 & 0 & 94 & 0 \\
\hline $\begin{array}{l}\text { Reticular Ery- } \\
\text { throcyte }(0 / 00)\end{array}$ & 24 & 22 & 29 & 59 & 31 & 29 & - & 28 & 19 & 6 & 17 & 27 \\
\hline $\begin{array}{l}\text { Specific gravity } \\
\text { of whole blood }\end{array}$ & 1.051 & 1.050 & 1.050 & 1.051 & 1.049 & 1.0545 & 1. 050 & 1.049 & 1.051 & 1.051 & 1.0525 & 1.054 \\
\hline Pigment Index & 0.88 & 1.05 & 1.05 & 0.98 & 1.03 & 1.2 & 0.83 & 1.01 & 1. 12 & 0.84 & 1. 10 & 1.19 \\
\hline $\begin{array}{l}\text { Mean Volume of } \\
\text { Blood Corpuscle }\end{array}$ & 80 & 108 & 102 & 102 & 114 & 111 & 103 & 100 & 111 & 93 & 105 & 112 \\
\hline
\end{tabular}

Examples in these view of the blood of workers are listed in Table 2 in which moderate decrease in the number of erythrocyte, the amount of hemoglobin, and the value of hematocrit along with a slight increase in reticular erythrocyte are found.

Although in some cases $\mathrm{H}$ bodies were not detected entirely, not a little cases revealed $\mathrm{H}$ bodies from about $1 \%$ to nearly $30 \%$ indication pretty large differences 


\section{STUDY ON HEINZ BODIES}

by persons. Among them, one case, who showed the emergence of $\mathrm{H}$ bodies in a comparatively high rate, was a fresh worker who had been working only for 16 days and complaining the ill condition of the body very hard.

Such fact that $\mathrm{H}$ bodies are readily found with high rate in workers not long from the commencement of this work is also attracting attention repeatedly in cases other than this, and the authors have found similar tendency also in several students working in the same factory in the summer vacation.

Accordingly on occasion of the emergence of $\mathrm{H}$ bodies in high rate for workers at factories, this may be regarded as a case of fresh workers or a case of accidental acute intoxication, because it is rather uncommon in practice to fine $\mathrm{H}$ bodies in persons in a long year service who has been experienced in the work and adaptate to the poison in some degree.

At all events, the detection of $\mathrm{H}$ bodies is an evidence for the sure influence of the action of poison upon the living body and enables the prediction of the succeeding anemia in some degree, and in this point lies the clinical signiflcance of $\mathrm{H}$ bodies.

\section{ConcLusion}

In regard to the relation between $\mathrm{H}$ bodies and methemoglobin, the view in histological chemistry, chemical conditions, clinical observation and others, the outline of the author's result were described with referrence to the past literatures.

The authors are willing to promote further the clinical as well as experimental examination on these points in the future.

\section{REFERENCES}

1) Heinz, R. (1890). Gifte, Arch. Klin. Med. (R Virchow), 122, 112.

2) Ehrlich, P. (1892). Verh. Congr. Inn. Med. 11, 33.

3) Groses, E., Bock, M. and Hellrung, F. (1924). Arch. Exp. Pathol. Pharmacoı., 200, 271.

4) Moeschlin, S. (1940). Schweiz. Med. Wochenschr., 70, 789.

5) Houston, I. B. and Barlow, A. M. (1959). Lancet, 7111, 1062.

6) Sprigo, A. I. and Smith, R.S. (1958). Lancet, 2029, 1039.

7) Kubota, S. (1954). J. Sci. Labour, 30, 283.

8) Yoshida, H. (1956). Acta Haematol. Jap. 19, 120.

9) Koyama, S. private letter.

10) Pernis, B. (1959). Bull. Hyg. 34, 1270.

11) Stewart, H. W. (1949). Blood, 4, 479.

12) Hartwich, W. (1912). Folia Haematol., 13, 257.

13) Suzuki, T. (1912). Folia Haematol., 13, 225.

14) Hugo, K. (1912). Folia Haematol., 14, 430.

15) Gutstein, M. and Wallbach, G. (1927). Virchows Arch. Pathol. Anat., 263, 741.

16) Webster, S. H., Lilijegren, E. J. and Zimmer, D. G. (1948). Stain Technol., 23, 97. 


\section{S. ISHIZU, M. MINAMI AND K. YAMAMURA}

17) Heubner, W. (1941). Klin. Wochenschr., 20, 137.

18) Heubner, W. (1943). Folia Haematol., 67, 323.

19) Kiess, M. and Seipelt, L. (1943). Arch. Exp. Pathol. Pharmakol., 200, 648.

20) Koike, S. private letter.

21) Monamey, B. J. and Dereck, R. (1950). Brit. J. Ind. Med, 7, 131.

22) Hughes, J. p. (1954). Arch. Ind. Hyg. Occup. Med., 10, 192.

23) Takemura, N. (1961). Jap. J. Ind. Health, 3,

24) Hartwich, W. (1912). Folia Haematol. Archiv., 13, 257.

25) Monamy, B. J. and Pereck, R. (1950). Brit. J. Ind. Med., 7, 131.

26) Koike, S. By private letter.

27) Aoki, H. (1954). Nissin Igaku, 41, 136. (in Japanese)

28) Ishizu, S. and Akiyama, K. (1953). J. Sci. Labour, 29, 527. (in Japanese) 